\title{
Subpicosecond luminescence spectroscopy of exciton localization in InxGa1-xN films
}

\section{AUTHOR(S):}

Kanemitsu, Yoshihiko; Tomita, Koichi; Inouye, Hideyuki

\section{CITATION:}

Kanemitsu, Yoshihiko ...[et al]. Subpicosecond luminescence spectroscopy of exciton localization in InxGa1-xN films. Applied Physics Letters 2005, 87(15): 151120.

\section{ISSUE DATE:}

2005-10

URL:

http://hdl.handle.net/2433/87363

\section{RIGHT:}

c 2005 American Institute of Physics. 


\title{
Subpicosecond luminescence spectroscopy of exciton localization in $\ln _{x} \mathrm{Ga}_{1-x} \mathrm{~N}$ films
}

\author{
Yoshihiko Kanemitsu ${ }^{\text {a) }}$ \\ International Research Center for Elements Science, Institute for Chemical Research, \\ Kyoto University, Uji, Kyoto 611-0011, Japan \\ Koichi Tomita \\ Graduate School of Materials Science, Nara Institute of Science and Technology, Ikoma, \\ Nara 630-0192, Japan \\ Hideyuki Inouye \\ International Research Center for Elements Science, Institute for Chemical Research, \\ Kyoto University, Uji, Kyoto 611-0011, Japan
}

(Received 16 June 2005; accepted 23 August 2005; published online 7 October 2005)

\begin{abstract}
We have studied the exciton localization dynamics in $\operatorname{In}_{x} \mathrm{Ga}_{1-x} \mathrm{~N}$ epitaxial films with different In compositions $(x=0.02,0.05$, and 0.09$)$ by means of optical Kerr-gate time-resolved photoluminescence (PL) spectral measurements. By changing excitation wavelength of 150 fs laser pulses, $\operatorname{In}_{x} \mathrm{Ga}_{1-x} \mathrm{~N}$ films are resonantly excited around their exciton energies at $6 \mathrm{~K}$. Under the resonant excitation, the PL dynamics is sensitive to the In composition of the sample and the excitation laser intensity. In the low In composition samples, the formation time of radiative excitons at localized states is $5-10 \mathrm{ps}$. In the high In composition samples, the gradual redshift of the PL peak energy is observed within several tens of picoseconds. The radiative recombination processes of excitons are discussed. (C) 2005 American Institute of Physics.

[DOI: 10.1063/1.2103407]
\end{abstract}

Recently, the development of both semiconductor crystal growth techniques and wavelength-tunable laser systems has enabled us to study the intrinsic and detailed optical processes in wide band gap semiconductors. Especially, in the past decade, there have been many experimental and theoretical studies on the optical properties of nitride semiconductors such as $\mathrm{GaN}, \mathrm{In}_{x} \mathrm{Ga}_{1-x} \mathrm{~N}$, and $\mathrm{Al}_{y} \mathrm{Ga}_{1-y} \mathrm{~N}$ crystals. ${ }^{1}$ It is well known that $\operatorname{In}_{x} \mathrm{Ga}_{1-x} \mathrm{~N}$ ternary alloys show high photoluminescence (PL) quantum efficiencies in spite of high threading dislocation defect density, ${ }^{2,3}$ and they are used as light-emitting-diode and laser materials in the blue wavelength region. The radiative recombination mechanism for efficient PL in $\operatorname{In}_{x} \mathrm{Ga}_{1-x} \mathrm{~N}$ films has been discussed by the passivation of defects by In (Ref. 4) and the exciton localization at potential minima. ${ }^{5-7}$ It has been suggested that potential minima for exciton localization in $\operatorname{In}_{x} \mathrm{Ga}_{1-x} \mathrm{~N}$ films are due to self-formed In-rich dots and islands. ${ }^{5-7}$ However, the localization dynamics of excitons into lower energy states in $\mathrm{In}_{x} \mathrm{Ga}_{1-x} \mathrm{~N}$ crystals is not clear. Time-resolved PL spectral measurements are one of the most useful methods for understanding the exciton localization dynamics and the radiative recombination processes in semiconductor mixed crystals. ${ }^{8-10}$

In this letter, we report the PL dynamics of $\operatorname{In}_{x} \mathrm{Ga}_{1-x} \mathrm{~N}$ epitaxial films at low temperatures by means of an optical Kerr method and a wavelength-tunable femtosecond laser system. By turning excitation photon energies, $\operatorname{In}_{x} \mathrm{Ga}_{1-x} \mathrm{~N}$ films are resonantly excited near their exciton energies. Under resonant excitation of the band edge of $\operatorname{In}_{x} \mathrm{Ga}_{1-x} \mathrm{~N}$ with different In compositions, the PL spectrum and dynamics

\footnotetext{
${ }^{a)}$ Author to whom correspondence should be addressed; also at: Graduate School of Materials Science, Nara Institute of Science and Technology, Ikoma, Nara 630-0192, Japan; electronic mail: kanemitu@scl.kyoto-u.ac.jp
}

depend on the In composition of $\operatorname{In}_{x} \mathrm{Ga}_{1-x} \mathrm{~N}$ films. It is pointed out that the PL dynamics of $\operatorname{In}_{x} \mathrm{Ga}_{1-x} \mathrm{~N}$ films is different from that of II-VI compound semiconductors. The exciton localization and recombination processes in $\mathrm{In}_{x} \mathrm{Ga}_{1-x} \mathrm{~N}$ will be discussed.

The samples used in this work were fabricated by the metalorganic chemical vapor deposition method. ${ }^{11,12}$ The thickness of $\operatorname{In}_{x} \mathrm{Ga}_{1-x} \mathrm{~N}$ epitaxial layers was $90 \mathrm{~nm}$ grown on a patterned sapphire substrate with a $5 \mu \mathrm{m} \mathrm{GaN}$ buffer layer. The In composition was varied from $x=0.02$ to 0.09 . Epitaxial films were used for the study of the nature of exciton localization in $\operatorname{In}_{x} \mathrm{Ga}_{1-x} \mathrm{~N}$ mixed crystals, because in the quantum well structures the PL spectrum contains an inhomogeneous broadening due to the fluctuation of the layer thickness. ${ }^{12,13}$

Wavelength-tunable femtosecond laser pulses were obtained from an optical parametric amplifier system based on a regenerative amplified mode-locked Ti:sapphire laser. The pulse duration and the repetition rate were $\sim 150 \mathrm{fs}$ and $1 \mathrm{kHz}$, respectively. For time-resolved PL spectrum measurements, an optical Kerr gate method was used with toluene as a Kerr medium in a quartz cell having $1 \mathrm{~mm}$ thickness. The time resolution was about $0.7 \mathrm{ps}^{14,15}$ The PL spectra were measured as a function of the delay time, using a liquid-nitrogen-cooled charged-coupled device with a $50 \mathrm{~cm}$ single monochromator. The sample temperature was kept at $6 \mathrm{~K}$ in all the PL measurements.

The PL spectra in all samples were measured under resonant excitation of the band edge of $\operatorname{In}_{x} \mathrm{Ga}_{1-x} \mathrm{~N}$ films with different In compositions, in order to avoid the direct excitation of the $\mathrm{GaN}$ buffer layer. If the photon energy of the excitation laser is above the band gap energy of the GaN buffer layer, the diffusion of the carriers from $\mathrm{GaN}$ buffer layer into $\operatorname{In}_{x} \mathrm{Ga}_{1-x} \mathrm{~N}$ epitaxial films occurs and the compli- 


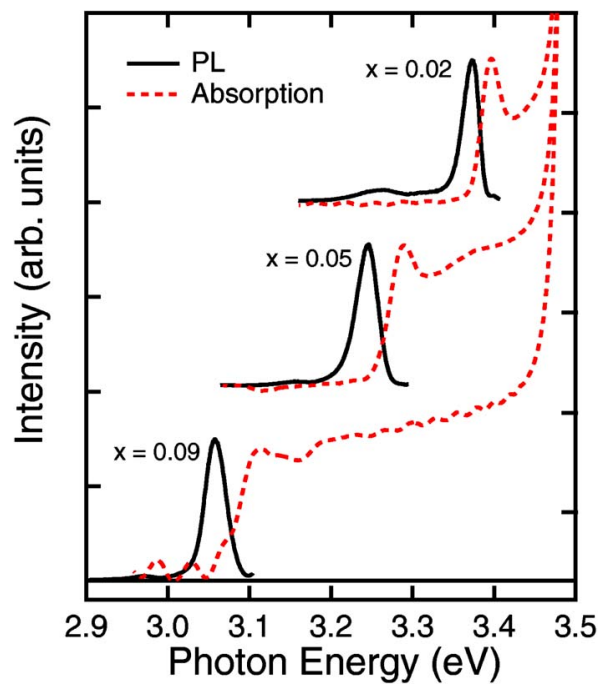

FIG. 1. (Color online) Optical absorption and PL spectra under $\sim 0.9 \mu \mathrm{J} / \mathrm{cm}^{2}$ femtosecond laser excitation in $\operatorname{In}_{x} \mathrm{Ga}_{1-x} \mathrm{~N}$ thin films.

cated PL dynamics is observed: The intrinsic energy relaxation processes in $\operatorname{In}_{x} \mathrm{Ga}_{1-x} \mathrm{~N}$ films cannot be studied under high photon-energy excitation. In our PL experiments, the excitation photon energy was set to $E_{x}+22 \mathrm{meV}$, where $E_{x}$ is the lowest free-exciton energy in each $\operatorname{In}_{x} \mathrm{Ga}_{1-x} \mathrm{~N}$ sample. Under the same excitation intensity, the initial electron temperatures are almost the same in all the samples. Here, PL properties of three different samples are reported in detail: The excitation photon energies were $3.421 \mathrm{eV}$ for the $x=0.02$ sample, $3.314 \mathrm{eV}$ for $x=0.05$, and $3.136 \mathrm{eV}$ for $x=0.09$.

Figure 1 shows optical absorption and time-integrated PL spectra of $\operatorname{In}_{x} \mathrm{Ga}_{1-x} \mathrm{~N}(x=0.02,0.05$, and 0.09) epitaxial films. In the absorption spectrum, the abrupt increase at around $3.5 \mathrm{eV}$ is due to the $\mathrm{GaN}$ buffer layer between the $\mathrm{In}_{x} \mathrm{Ga}_{1-x} \mathrm{~N}$ film and the sapphire substrate. The exciton absorption peak and the PL peak in $\operatorname{In}_{x} \mathrm{Ga}_{1-x} \mathrm{~N}$ films are clearly observed in our samples. With an increase of the In composition ratio, both the lowest absorption and PL peaks shift to lower energy. In all samples, there is a Stokes shift between the absorption and PL peaks. The observed Stokes shifts are 20-50 meV at low temperatures. The Stokes shift tends to increase with increasing In composition. This large Stokes shift means that there exist localized states in $\operatorname{In}_{x} \mathrm{Ga}_{1-x} \mathrm{~N}$ films. In order to clarify the localization process of excitons, we have measured the PL dynamics of $\operatorname{In}_{x} \mathrm{Ga}_{1-x} \mathrm{~N}$ film under resonant excitation.

Figure 2 shows time-resolved PL spectra of $\operatorname{In}_{x} \mathrm{Ga}_{1-x} \mathrm{~N}$ films $(x=0.02,0.05$, and 0.09$)$ at different excitation intensities $\left(110,230\right.$, and $\left.460 \mu \mathrm{J} / \mathrm{cm}^{2}\right)$ and at $6 \mathrm{~K}$. The PL dynamics is sensitive to the In composition of the $\operatorname{In}_{x} \mathrm{Ga}_{1-x} \mathrm{~N}$ samples. In the low In composition sample $(x=0.02)$, the PL appears after a certain delay time. The PL delay time is about $10 \mathrm{ps}$ at $110 \mu \mathrm{J} / \mathrm{cm}^{2}$ and decreases with an increase of the excitation intensity. The photoexcited carriers exist the delocalized states just after the laser excitation. The electrons or holes are trapped at localized states and then radiative excitons are formed at localized states. It is believed that the PL delay time corresponds to the formation time of excitons at localized states.

In the $x=0.05$ sample, the PL dynamics is also sensitive to the excitation intensity, similar to the cases of the Downloaded 16 Nov 2009 to 130.54 .110 .32 . Redistribution subject

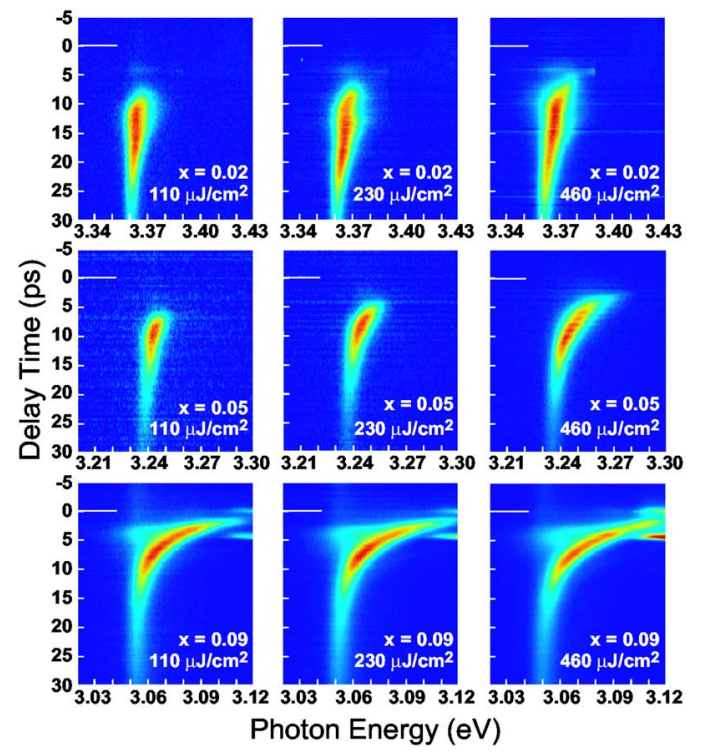

FIG. 2. (Color online) Temporal changes of the PL spectra of $\operatorname{In}_{x} \mathrm{Ga}_{1-x} \mathrm{~N}$ thin films $(x=0.02,0.05$, and 0.09$)$ under the resonant excitation at different excitation intensities of 110,230 , and $460 \mu \mathrm{J} / \mathrm{cm}^{2}$ at $6 \mathrm{~K}$.

$x=0.02$ sample. At low intensities, there is the formation time for the radiative exciton, and this formation time is shorter than that of the $x=0.02$ sample. With an increase of the excitation intensity, the PL appears abruptly and the redshift of the PL peak energy is clearly observed.

In the high In composition sample $(x=0.09)$, a large and rapid redshift of the PL peak energy is clearly observed during 20-30 ps after the laser excitation. The continuous redshift of the PL peak energy is observed at different excitation intensities. This dynamical behavior of the $x=0.09$ sample is different from those of the $x=0.02$ and 0.05 samples. The composition dependence of the PL spectrum shows that the band-tail states with large density of states are formed, with an increase of the In composition in $\operatorname{In}_{x} \mathrm{Ga}_{1-x} \mathrm{~N}$ films.

Figure 3 shows, in more detail, PL spectra as a function of the delay time in the $x=0.09$ sample at $460 \mu \mathrm{J} / \mathrm{cm}^{2}$ and at $6 \mathrm{~K}$. The normalized PL spectra are shown in the figure. At the initial stage, the PL spectrum is very broad and shows an asymmetric shape with a tail at the high energy side. With an increase of the time delay, the PL band width becomes narrower and symmetrical. This behavior can be explained by a picture that radiative excitons relax into the lower energy states and the cooling of the electron temperature occurs during the exciton localization in band-tail states. The significant redshift of the PL peak energy occurs within about 10 ps. The PL peak reaches to the PL peak energy which is observed in time-integrated PL spectra (the upper PL spectrum in Fig. 3) at the delay time of about 20 ps. The rapid and large relaxation of excitons occurs within several tens of picoseconds, and the localized states show efficient PL.

Let now us discuss the exciton localization process in $\mathrm{In}_{x} \mathrm{Ga}_{1-x} \mathrm{~N}$ films. The observed time-dependent spectral shift clearly shows that radiative excitons migrate into lower localized states in $\operatorname{In}_{x} \mathrm{Ga}_{1-x} \mathrm{~N}$ films. This behavior is usually observed in other semiconductor ternary alloys such as II-VI compounds. ${ }^{16}$ It is believed that at low temperatures the exciton migration between the localized states is caused by the acoustic phonon assisted hopping similar to the case of II-VI compound semiconductor mixed crystals, ${ }^{9}$ because the LO to AIP license or copyright; see http://apl.aip.org/apl/copyright.jsp 


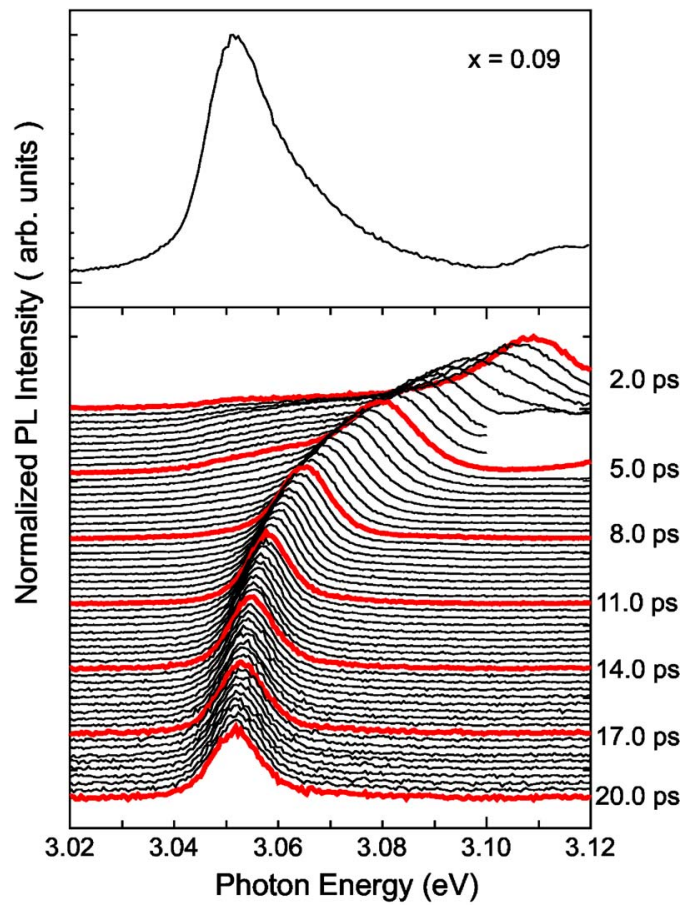

FIG. 3. (Color online) Temporal changes of PL spectra of the $\operatorname{In}_{x} \mathrm{Ga}_{1-x} \mathrm{~N}$ $(x=0.09)$ thin film at $460 \mu \mathrm{J} / \mathrm{cm}^{2}$ and at $6 \mathrm{~K}$. The upper PL spectrum is the time-integrated one.

phonon energy in $\mathrm{GaN}$ based materials is much larger than the observed luminescence Stokes shift. However, the dynamical behaviors of exciton localization in $\operatorname{In}_{x} \mathrm{Ga}_{1-x} \mathrm{~N}$ are completely different from those in II-VI mixed crystals, as will be discussed later.

In II-VI compound semiconductors such as $\mathrm{CdS}_{1-x} \mathrm{Se}_{x}$ and $\mathrm{ZnS}_{1-x} \mathrm{Se}_{x}$ crystals, ${ }^{8-10,16}$ alloy disorder causes the exponential band-tail states and the redshift of the PL peak energy is observed in the nanosecond time scale. In II-VI semiconductor mixed crystals, the exciton migrations gradually occur in band-tail states. On the other hand, in the $\mathrm{In}_{x} \mathrm{Ga}_{1-x} \mathrm{~N}$ crystals, the large shift of the PL spectrum occurs in the picosecond time region, and the PL peak reaches to the PL peak energy which is observed in time-integrated PL spectra within 20-30 ps. In addition, the Stokes shift of $\operatorname{In}_{x} \mathrm{Ga}_{1-x} \mathrm{~N}$ films is much larger than that of $\mathrm{CdS}_{1-x} \mathrm{Se}_{x}$ crystals. Then, the energy relaxation rates of excitons in $\operatorname{In}_{x} \mathrm{Ga}_{1-x} \mathrm{~N}$ films are much larger than that of II-VI mixed crystals. We would like to point out that the very rapid localization of excitons causes no long-range diffusion of excitons to nonradiative recombination centers (Refs. 7 and 17) and thus this is related to high efficient $\mathrm{PL}$ in $\mathrm{In}_{x} \mathrm{Ga}_{1-x} \mathrm{~N}$ films.

Furthermore, it is believed that the very rapid relaxation of excitons causes the rapid filling of the localized states in $\mathrm{In}_{x} \mathrm{Ga}_{1-x} \mathrm{~N}$ films. Under intense laser excitation, the localized states are saturated and then a large number of carriers exist in the delocalized states near the band edge. $\mathrm{In} \mathrm{In}_{x} \mathrm{Ga}_{1-x} \mathrm{~N}$ samples, the stimulated emission appears at the higher energy region of the localized states under intense excitation. ${ }^{18,19}$ On the other hand, in II-VI mixed crystals and II-VI semiconductor quantum wells (for example, $\mathrm{CdZnS}-\mathrm{ZnS}$ and $\mathrm{CdZnSe}-\mathrm{ZnSe}$ structures), the stimulated emission appears at the lowest energy of the localized states under intense excitation. ${ }^{20-22}$ There is a large difference in the exciton localization dynamics and optical gains between
II-VI and III-nitride ternary alloys. It is believed that these different optical processes are caused by the different origin of the localized states. The formation of localized states in $\mathrm{In}_{x} \mathrm{Ga}_{1-x} \mathrm{~N}$ films is due to self-formed In-rich dots and islands, rather than alloy disorders in II-VI compounds. Further experiments are needed for the understanding of the nature of the band-tail states in $\operatorname{In}_{x} \mathrm{Ga}_{1-x} \mathrm{~N}$ ternary alloys. At the present stage, it is concluded that the very rapid relaxation and no long-range diffusion of excitons cause efficient and unique luminescence of $\operatorname{In}_{x} \mathrm{Ga}_{1-x} \mathrm{~N}$ ternary alloys.

In conclusion, we have studied the PL dynamics of $\mathrm{In}_{x} \mathrm{Ga}_{1-x} \mathrm{~N}$ films under the resonant excitation near the band edge at low temperatures. Under the resonant excitation, the PL spectrum and dynamics are sensitive to the In composition of the sample. The large energy relaxation of radiative excitons occurs in the picosecond time region. It is pointed out that the rapid localization of excitons in localized states is related to the efficient luminescence in $\operatorname{In}_{x} \mathrm{Ga}_{1-x} \mathrm{~N}$ films and that the exciton localization dynamics in $\operatorname{In}_{x} \mathrm{Ga}_{1-x} \mathrm{~N}$ is different from that in II-VI mixed crystals.

The authors would like to thank Professor Y. Yamada of Yamaguchi University for useful discussions. This work was supported in part by the Research Foundation of Opto-Science and Technology and The Futaba Electronics Memorial Foundation.

${ }^{1}$ S. Nakamura, S. Pearton, and G. Fasol, The Blue Laser Diode (Springer, Berlin, 2000).

${ }^{2}$ S. Nakamura, M. Senoh, N. Iwasa, and S. Nagahama, Jpn. J. Appl. Phys., Part 2 34, L797 (1995).

${ }^{3}$ S. Nakamura, Science 281, 956 (1998).

${ }^{4}$ Y. Narukawa, Y. Kawakami, M. Funato, Sz. Fujita, Sg. Fujita, and S. Nakamura, Appl. Phys. Lett. 70, 981 (1999).

${ }^{5}$ S. Chichibu, T. Azuhata, T. Sota, and S. Nakamura, Appl. Phys. Lett. 69, 4188 (1996).

${ }^{6}$ Y. Narukawa, Y. Kawakami, Sz. Fujita, Sg. Fujita, and S. Nakamura, Phys. Rev. B 55, R1938 (1997).

${ }^{7}$ A. Kaneta, T. Mutoh, Y. Kawakami, S. Fujita, G. Murutsuki, Y. Narukawa, and T. Mukai, Appl. Phys. Lett. 83, 3462 (2003), and references therein. ${ }^{8}$ E. Cohen and M. D. Sturge, Phys. Rev. B 25, 3828 (1982).

${ }^{9}$ J. A. Kash, A. Ron, and E. Cohen, Phys. Rev. B 28, 6147 (1983).

${ }^{10}$ C. Gourdon and P. Lavallard, Phys. Status Solidi B 153, 641 (1989).

${ }^{11}$ K. Tadatomo, H. Okagawa, Y. Ohuchi, T. Tsunekawa, Y. Imada, M. Kato, and T. Taguchi, Jpn. J. Appl. Phys., Part 2 40, L583 (2001).

${ }^{12}$ C. Sasaki, H. Naito, M. Iwata, H. Kudo, Y. Yamada, T. Taguchi, T. Jyouichi, H. Okagawa, K. Tadatomo, and H. Tanaka, J. Appl. Phys. 93, 1642 (2003)

${ }^{13}$ Y. Yamada, Y. Ueki, K. Nakamura, T. Taguchi, Y. Kawaguchi, A. Ishibashi, and T. Yokogawa, Appl. Phys. Lett. 84, 2082 (2004).

${ }^{14}$ T. Nagai, T. J. Inagaki, and Y. Kanemitsu, Appl. Phys. Lett. 84, 1284 (2004).

${ }^{15}$ T. Nagai, A. Yamamoto, and Y. Kanemitsu, Phys. Rev. B 71, 121201(R) (2005).

${ }^{16}$ S. Permogonov, A. Renznitskii, S. Verbin, G. O. Muller, P. Flogel, and M. Nikiforova, Phys. Status Solidi B 113, 589 (1982).

${ }^{17}$ D. Cherns, S. J. Henley, and F. A. Ponce, Appl. Phys. Lett. 78, 2691 (2001).

${ }^{18}$ A. Satake, Y. Masumoto, T. Miyajima, T. Asatsuma, and M. Ikeda, Phys. Rev. B 60, 16660 (1999).

${ }^{19}$ E. Kuokstis, J. W. Yang, G. Simin, M. Asif Khan, R. Gaska, and M. S. Shur, Appl. Phys. Lett. 80, 977 (2002).

${ }^{20}$ Y. Yamada, Y. Masumoto, J. T. Mullins, and T. Taguchi, Appl. Phys. Lett. 61, 2190 (1992)

${ }^{21}$ J. Ding, H. Jeon, T. Ishihara, M. Hagerott, A. V. Nurmikko, H. Luo, N. Samarth, and J. Furdyna, Phys. Rev. Lett. 69, 1707 (1992).

${ }^{22} \mathrm{In} \mathrm{GaN}$, the stimulated emission line appears at the low energy region. Under intense laser excitation, the power dependence of the PL spectrum in $\mathrm{GaN}$ is similar to that in II-VI compounds (Refs. 14 and 15). InGaN ternary alloys show unique PL properties. 